\title{
Internacional Socialista. Contradicciones e incoherencias de su presencia en América Latina y el Caribe
}

Gregorio Selser

\begin{abstract}
19 In 1951, la Internacional Socialista fue reconstituida luego de los enormes trastornos de la Segunda Guerra Mundial. En ese momento, recién se habia dado inicio a la descolonización y el movimiento era básicamente europeo, tanto en sus miembros como en su perspectiva. Sin embargo, uno de los logros más perdurables de la Declaración de la Internacional de Frankfurt de 1951, fue y sigue siendo el que se haya insistido claramente respecto a la crítica importancia de la libertad como medio y fin de nuestros principios.

"Ha llegado nuevamente el momento de reformular aquellos principios. El mundo ha cambiado desde 1951 y nosotros también. Hemos vivido la internacionalización sin precedentes de la economia mundial; hemos participado en gobiernos democráticos y en transformaciones revolucionarias buscando lograr la autonomía nacional o el progreso hacia el socialismo y debemos hacer todos los esfuerzos posibles por aprender las lecciones tanto de nuestras victorias como de nuestras derrotas."l

Hemos escogido estos párrafos pertenecientes a uno de los documentos aprobados al término del XVII Congreso de la Internacional Socialista (IS) como punto de partida de un análisis que se propone abordar las orientaciones y proclividades más recientes de ese movimiento pluralista mundial en relación con los países de América Latina y el Caribe. Esta reunión precederá a la que está anunciada para 1988, en Oslo, Noruega, en la que se considerará, después de una laboriosa gestación, el programa que reemplazará al de Frankfurt al cabo de más de treinta y cinco años, pensado para Europa por europeos en el clímax de la Guerra Fría.

Si el mundo cambió y también se transformaron los partidos de la Is, no fue mucho lo que le tocó en suerte, por tal mudanza, a Hispanoamérica, a sus pueblos y a sus partidos de denominación socialista o de orientación socialdemócrata. Las "transformaciones revolucionarias" en procura de la autonomía nacional, o el "progreso hacia el socialismo" mencionados en el documento como loables conquistas del socialismo democrático europeo, continúan siendo una aspiración más, cuando no un sueño en no pocas oportunidades frustrado entre la mayoría de los paises del Tercer Mundo, incluidos los del hemisferio occidental.

Precisamente durante la celebración del Congreso en Lima, se registraron dramáticos y tremendos sucesos en establecimientos carcelarios peruanos, con un saldo cuantioso de muertos y heridos por efectos de una desaforada represión policíacomilitar de moti-
\end{abstract}

1 El Mandato de Lima, documento del XVII.Congreso de la Internacional Socialista. Lima, Perú, 20-23 de junio de 1986, Mimeo, 4 p. 
vación políticosocial y cuyos autores fueron severamente enjuiciados por el propio presidente Alán García. El presidente de la IS, Willy Brandt, debió adelantar en muchas horas el momento de la clausura del cónclave. No imaginaron los asambleistas el escenario marginal en que iban a desarrollar su cometido. Por el contrario, pocas veces como en esta ocasión tuvieron oportunidad de ilustrarse, in situ, acerca de la naturaleza del ancestral conflicto de clases y sus manifestaciones de violencia extrema en uno de los países que, simbólicamente, proporcionaba a los memoriosos la ocasión de reflexionar sobre dos importantes expresiones del pensamiento y la práctica socialistas en América Latina: José Carlos Mariátegui y Víctor Raúl Haya de la Torre.

A ambos se refirió en su discurso inaugural el presidente García. Al primero con respeto intelectual, al segundo con adhesión militante y partidaria. El Partido Aprista Peruano deriva su apelativo de APRA, Alianza Popular Revolucionaria Americana, fundada por Haya en mayo de 1924, recuérdeselo al caso, y su vigencia tiene particularidad localista a despecho de su invocación continentalista, que es hoy una remembranza arqueológica. El pensamiento de Mariátegui, fundador del Partido Comunista peruano, persiste hasta hoy como fuente de inspiración ideológica que trasciende la frontera patria e influye como aporte científico social de obligada consulta.

En plena explosión de violencia castrense, García debió disertar no sólo acerca de los trágicos episodios de su patria, sino hacer referencias explícitas a la más grave crisis económicofinanciera y social de la historia del Continente:

Esta es la primera ocasión en la que un congreso mundial socialista se realiza en América Latina, convirtiéndola así en el escenario de un diálogo histórico entre quienes vienen de los pueblos más ricos y desarrollados de la vieja Europa y quienes representamos a los países del Tercer Mundo, a los que llegó el capitalismo como dominación imperialista y a los que, a comienzos de siglo, llegó el mensaje socialista planteándose como una solución. Aquí estamos con diferentes nombres y doctrinas, buscando identificar los objetivos comunes de nuestras luchas, pero de otro lado reconociendo la diversidad cambiante de nuestros pueblos y nuestras historias.

Y lo asumimos cuando la deuda externa agobia a los pueblos pobres, cuando el poder económico de los países ricos muestra sus limitaciones mundiales, cuando el imperialismo amenaza a los más débiles, cuando la carrera armamentista de los grandes y los chicos muestra la irracionalidad profunda de nuestra época, cuando los fundamentalismos ideológicos parecen llevarnos a la muerte. ${ }^{2}$

Dio además énfasis a tales puntualizaciones, al añadir que su patria afrontaba "la crisis más profunda de la historia", como consecuencia de "muchos años de dominación, injusticia y error"; que su gobierno "mantendrá sin dar marcha atrás su posición respecto a la deuda externa que agobia a los países más pobres impidiendo su desarrollo y no se rendirá ante el Fondo Monetario Internacional"; y que "mantendrá invariable su defensa de la

2 Alán Garcia, Mensaje de inauguración del XVII Congreso de la Internacional Socialista, Lima, Mimeo, 22 p. 
soberanía continental amenazada por el intervencionismo imperialista en Centroamérica y apoyará sin reservas ni subterfugios la causa revolucionaria del pueblo de Nicaragua".

\section{Circunloquios y omisiones}

De los más de 60 partidos que pertenecen a la is -de los cuales más de una veintena están hoy en funciones de gobierno y otros desempeñando el papel de fuerte oposición- participaron en la reunión de Lima los representantes de 41 partidos y movimientos afines, además de decenas de observadores e invitados.

A ellos, con su característica moderación coloquial, Brandt les expresó su complacencia por el hecho de que la democratización de América Latina "haya avanzado tanto en los últimos años", se congratuló porque "hemos podido aportar una pequeña contribución a este proceso y seguramente no descansaremos antes de que Chile y Paraguay se hayan liberado de las cadenas de la dictadura, ni tampoco antes de que Centroamérica, libre de intervenciones militares, pueda seguir su propio camino". Más discutiblemente postuló que se debía "reconocer que los Estados Unidos han fomentado la democratización de algunos países latinoamericanos -no mencionó cuáles- así como la destitución del régimen de Marcos en Filipinas'. Siguió con estos párrafos:

En los años recientes hemos tenido que centrar nuestra atención, reiteradamente, en la crisis centroamericana. No fue por deseo nuestro. Nuestros socios centroamericanos, al igual que los de Washington, nos han dado su visión sobre este tema. Digo esto con plena conciencia del hecho de que la relación entre Norte y Sur, vista desde la óptica del Tercer Mundo, adquiere una dimensión diferente de la que tiene la mayoría de los europeos. Sin embargo, pienso que podemos estar de acuerdo en afirmar que el mesianismo siempre ha demostrado ser catastrófico. Y cabe añadir que el derecho de gentes no obliga sólo a los Estados pequeños sino también a los grandes, pues no es un derecho de dos clases. En todo caso, nuestro mundo necesita menos intervenciones al estilo de la de Nicaragua u ocupaciones al estilo de la de Afganistán.

Me parece importante, en este momento, que alentemos la iniciativa de paz surgida en la misma región. Me refiero al proceso de Contadora, incluyendo al Grupo de Apoyo sudamericano. Esta iniciativa merece todo el estímulo y fomento de nuestra Internacional Socialista, especialmente por parte de sus partidos europeos. ${ }^{3}$

Los circunloquios y anfibologías fueron en esta ocasión no menos sugestivos que las omisiones, aun cuando el saldo de su formulación aparezca como positivo a partir de que insistió, como lo hizo en otros congresos y reuniones habituales de la IS, en que la visión correcta interpretativa era la de Norte-Sur, descartando tácitamente la reaganiana tesis Este-Oeste a la que se están plegando no pocos partidos socialdemócratas europeos, incluyendo algunos dirigentes del suyo propio, el Sozialdemokratische Partei Deutschlands (SPD).

Predominó en los discursos la tónica de apoyo a las revolucio-

${ }^{3}$ Willy Brandt, Ponencia ante el XVII Congreso de la Internacional Socialista, 20 de junio de 1986, Mimeo, versión española, $17 \mathrm{p}$. 
nes de Nicaragua y El Salvador, en no pocos casos con ciertas reticencias y en alguna ocasión con una franca tónica censora para el gobierno sandinista, como lo fue la del dirigente Carlos Andrés Pérez, de Acción Democrática Venezolana. Más notable se hizo por cuanto al propio tiempo encontró motivos de complacencia y beneplácito para con el régimen de José N. Duarte en El Salvador, lo que suscitó una disidente y disgustada requisitoria de Guillermo Ungo, del Movimiento Nacional Revolucionario (MNR).

Este incidente da oportuno pie para abordar el análisis de recientes procesos politicoideológicos registrables entre los partidos latinoamericanos y caribeños que forman parte de la is y que, de acuerdo con la nómina actualizada hasta junio de 1986 son los siguientes:

\section{MIEMBROS PLENOS}

Argentina. Partido Socialista Popular (PSP)

Barbados. Barbados Labour Party (BLP)

Chile. Partido Radical (PR)

Costa Rica. Partido Liberación Nacional (PLN)

Ecuador. Partido Izquierda Democrática (PID)

El Salvador. Movimiento Nacional Revolucionario (MNR)

Granada. New Jewel Movement (NJM)

Guatemala. Partido Socialista Democrático (PSD)

Jamaica. People's National Party (PNP)

Paraguay. Partido Revolucionario Febrerista (PRF)

República Dominicana. Partido Revolucionario Dominicano (PRD)

Venezuela. Acción Democrática (AD)

\section{MIEMBROS CONSULTIVOS}

Aruba NA. Movimiento Electoral di Pueblo (MEP)

Bolivia. Movimiento Izquierda Revolucionaria (MIR)

Brasil. Partido Democrático Trabalhista (PDT)

Curacao NA. Movementu Antiyas Nobo (MAN)

Guyana. Working People's Alliance (WPA)

Panamá. Partido Revolucionario Democrático (PRD)

Perui. Partido Aprista Peruano (PAP)

Puerto Rico. Partido Independentista Puertorriqueño (PIP)

St. Lucia. Progressive Labour Party (PLP)

Es sugestivo que de veinte partidos, agrupaciones y movimientos que integran la nómina, solamente dos -Argentina y Guatemala- ostenten la nomenclatura "socialista". Para los panegiristas de la naturaleza variada de los componentes de la organización, esta heterogeneidad de indoles, procedencias, plataformas y orientaciones es una demostración de su riqueza y desinhibido plura-

\footnotetext{
4 Esta agrupación, conocida como "Secretaría García Costa", tiene su afiliación suspendida desde 1981, por decisión del Buró de la IS reunido en París. Teóricamente al menos, pues subsiste la representación y membrecía.

${ }^{5}$ La invasión a Granada por Estados Unidos en octubre de 1983 so pretexto de una conmoción interna en la isla -en la que fue muerto Maurice Bishop, máximo dirigente del NJM y primer ministro de la isla- no canceló la representación del partido de la "Nueva Joya", que no designa a una gema como erróneamente se cree, sino que corresponde a la sigla del nombre original del movimiento cuando fue creado en 1972, Joint Endeavor for Welfare, Education and Liberation (JEWEL $=$ Esfuerzo Conjunto para el Bienestar, la Educación y la Liberación).
} 
lismo. El detalle de la no exigencia de una pertenencia formal o real a partidos de indudable ideología socialista, socialdemócrata o, como se está prefiriendo en los años recientes, socialista democrática, queda soslayado por la convención de que sean "partidos afines" a aquellas caracterizaciones.

Esto consiente una generosa diversidad a cuyo socaire pueden suscribirse organizaciones que difícilmente resistirian, por su ideología y por su actuación política y social, un examen serio a la luz de los conceptos fundamentales e históricos del socialismo. Es a partir de este tipo de licencias y concesiones que se registran notorias incoherencias, sobre todo en circunstancias clave de politica interna e internacional en las cuales el respeto a la normatividad del socialismo más elemental queda totalmente desvirtuado, si no burlado o deslucido, por los partidos miembros que están en función de gobierno. $Y$ es en tales situaciones en las que se patentizan las contradicciones y ambigüedades -no menos que las inconsecuencias- entre lo que se declama y lo que se practica.

\section{Agresiones $y$ adhesiones}

Durante una entrevista con la investigadora académica Felicity Williams, autora de una excelente obra acerca de la is en el hemisferio occidental, ${ }^{6}$ nos puntualizó que "muchos laboristas británicos estuvieron de acuerdo con la invasión a Granada, país gobernado por un partido miembro de la Internacional Socialista y, peor aún, fue la actitud de otro partido miembro, además en el gobierno, el Barbados Labour Party, que participó directamente en la invasión y ocupación de la isla por Estados Unidos". Agregó Williams:

Podemos afirmar que Reagan logró indirectamente, a través de la invasión a Granada (con independencia de los graves errores dentro del New Jewel que dieron pretexto a la invasión), desprestigiar a los líderes más progresistas de la is -por lo menos durante algunos meses-que estaban avalando el apoyo a la isla, a los sandinistas nicaragüenses y a la insurgencia salvadoreña. Tampoco debe olvidarse el voto aprobatorio a la invasión, que en el Parlamento Europeo acordó a Estados Unidos un alto porcentaje de diputados pertenecientes a partidos socialdemócratas, un hecho que refleja el peso de la influencia estadunidense y el grado de presión que puede ejercer en Europa.

De este tipo de situaciones sobreabundan los ejemplos. En 1984 el principal dirigente socialista de Portugal convocó a una reunión de partidos de la is en Lisboa, con el propósito fundamental de que sirviese de foro a líderes de la contrarrevolución armada nicaragüense, entre ellos a Edén Pastora. El propósito quedó frustrado por la activa oposición de muchos representantes de partidos latinoamericanos.

Al término del XV Congreso de la is celebrado en Madrid en noviembre de 1980, a propuesta de Willy Brandt, quedó consti-

\footnotetext{
- Felicity Williams, La Internacional Socialista y América Latina. Una visión critica. México. Universidad Autónoma Metropolitana (UAM), Unidad Azcapotzalco, 1984.

Cf. entrevista en El Dia. México, 16 de octubre de 1984.
} 
tuida una comisión de apoyo a la revolución nicaragüense con la presidencia de Felipe González, principal dirigente del Partido Socialista Obrero Español (PSOE). Un seguimiento de la actuación de ese organismo y de su titular permite afirmar que en el curso de seis años y salvo brevísimas y muy espaciadas visitas de dirigentes del PSOE a Nicaragua, no hubo demostración efectiva alguna de esa solidaridad. Peor aún, el bloque parlamentario del PSOE recibió instrucciones precisas de no suscribir documento público alguno de censura a las actuaciones y agresiones de la administración Reagan contra Nicaragua y, entre otras actitudes de parecido tenor, en 1984 el PSOE "desconvocó" a último momento una manifestación popular pluralista de apoyo a Nicaragua, a la que inicialmente había declarado su apoyo. Aun así, cien mil madrileños salieron a la calle para expresar su sentir.

Una ocasión, entre tantas, en las que el eurocentrismo elemental de los partidos de la is tuvo ocasión de expresarse con análogo mecanismo, ocurrió con motivo del enfrentamiento armado entre Gran Bretaña y Argentina a propósito de la posesión de las islas Malvinas (abril-junio de 1982). No obstante la insistencia de representantes latinoamericanos en la reunión del Buró de la is en Helsinki -26-28 de mayo- los delegados del Partido Laborista Británico, apoyados por la mayoría de sus colegas de los partidos europeos, bloquearon toda mención del conflicto y sólo se aceptó designar una comisión de estudio para que se expidiera... en el primer semestre de 1983.

En América Latina, pocos casos ilustran con mayor diafanidad esas y otras inconsecuencias que el del Partido Liberación Nacional (PLN) de Costa Rica. Felicity Williams menciona este caso famoso en su tiempo:

Cuando el PLN de Costa Rica bajo Francisco Orlich, contribuye en 1965 a la Fuerza Interamericana de.Paz en la intervención de la República Dominicana, con una veintena de policias, para asegurar la derrota de [la revolución constitucionalista desatada por el PRD], esa contribución sólo puede calificarse de traición, en vista de que [el presidente Juan] Bosch había sido electo democráticamente, al mismo tiempo que había sido miembro del mismo "movimiento socialdemócrata latinoamericano" a que pertenecía el PLN. ${ }^{8}$

Es cierto que el envío de los 21 policías fue un gesto simbólico y que a los efectos de la represión popular instaurada por Estados Unidos en Santo Domingo resultó irrelevante. Pero para el presidente Lyndon B. Johnson, que decidió la invasión, fue de capital importancia en vista de la tormenta política desatada en el mundo entero por esta nueva muestra de desprecio por el derecho internacional. Se sirvió de la Organización de Estados Americanos (OEA) para corregir su desaguisado y ésta a su vez inventó una Fuerza Interamericana de Paz (FIP) para reemplazar velozmente a las tropas de la Unión en la isla. Como lo puntualiza un historiador italo-norteamericano," "sólo seis naciones latinoamericanas enviaron contingentes a la FIP: Brasil, 1152 hombres; Honduras, 250;

\footnotetext{
${ }^{8}$ Felicity Williams, op. cit., p. 227-228.

${ }^{9}$ Piero Gleijeses. The Dominican Crisis. The 1965 Constitutionalist Revolt and American Intervention. Baltimore, Md., The John Hopkins University Press, 1978, p. 262.
} 
Paraguay, 178; Nicaragua, 159; Costa Rica, 21; y El Salvador, 3. Los tontons macoutes haitianos estuvieron ausentes de la FIP. Esto resultó infortunado, porque habrian estado en buena compañia. Soldados de cinco dictaduras marcharon hombro a hombro en Santo Domingo en defensa de la 'democracia' dominicana. Y con ellos iban veintiún policias costarricenses, una grotesca contribución a esta farsa internacional".

Williams agrega a su turno: "El PLN fue y probablemente es el partido latinoamericano afiliado a la is más pronorteamericano y ve a los Estados Unidos como el mejor defensor de la 'democracia', de la misma manera en que la mayoría de los partidos socialdemócratas europeos veían a Estados Unidos durante los peores momentos de la Guerra Fria." Y acota que meses más tarde el Latin American Liaison Bureau de la is destacó en Socialist International Information, tras mencionar que "una fuerza de marines de Estados Unidos intervino" en la República Dominicana, los partidos miembros de la IS, la IS misma y partidos amistosos de América Latina "ejercieron una constante presión internacional para la restauración del proceso constitucional", lo que condujo a la designación de un presidente provisional (Héctor García Godoy), que llamó a elecciones [...]. No hay mención del papel de su partido afiliado, el PLN de Costa Rica, en esta versión historiográfica socialdemócrata; y si el otro partido gobernante afiliado a la is en ese entonces, AD de Venezuela, se abstuvo de votar a favor de la intervención de la FIP en el foro de la OEA, otros gobiernos que se opusieron a dicha intervención (México, Chile, Uruguay, Ecuador y Perú), no estaban ni afiliados a la is ni tenian conexiones significativas con aquélla, y hasta podían ser de corrientes políticas diferentes, como la de la democracia cristiana. ${ }^{10}$

\section{La gestación y el fruto}

No nos proponemos graficar con apenas esa historia particular lo que podria entenderse, equívocamente, como una de las tendencias subyacentes en el quehacer de los partidos y organizaciones que integran la is en el ámbito latinoamericano y caribeño. Si puediera haberla, tiene que ver con la génesis misma y el desarrollo ulterior del movimiento.

Desde la asamblea constitutiva de Francfort del Meno en 1951 y salvo la tímida relación establecida en 1955 a través del Secretariado Latinoamericano, con sede en Uruguay, la vinculación de los partidos socialistas de Europa con sus homólogos de Hispanoamérica fue esporádica e inorgánica. Hasta 1970, la Is se concentró exclusivamente en el escenario europeo. Sus vínculos con los partidos de países del Tercer Mundo eran escasos y precarios y, por lo que respecta al hemisferio occidental, sólo estaban reconocidos como miembros plenos el Partido Socialista Popular (PSP) de Argentina -escisión de una de las corrientes en que se dividió el Partido Socialista Argentino en los años 60- y el People's National Party (PNP) de Jamaica. ${ }^{11}$

${ }^{10}$ Felicity Williams, op. cit., p. 227-229.

" Una descripción más amplia del proceso de salto cuantitativo de la IS hacia el hemisferio occidental puede ser consultado en Gregorio Selser, "Presencia de la 
Una variable la constituían los partidos admitidos como "observadores"-nombre después modificado por el de "consultivos"-, a saber: Acción Democrática (AD) y Movimiento Electoral del Pueblo (MEP) de Venezuela, y el Partido Aprista Peruano (PAP). El desequilibrado peso de la atención hacia afuera de la is en favor del propio, que el profesor Carlos Morales denomina "europeizante", se fue modificando en el transcurso de la década hasta alcanzar el desenvolvimiento que hoy ostenta:

\begin{abstract}
No era lógico ni sensato que una entidad que se dice "internacional" estuviera circunscrita a desarrollar su actividad en un solo continente, pues esto inhibia a muchos movimientos políticos no europeos que trataban de afiliarse [...] Era necesario que la is cambiara su accionar [...] Vale la pena puntualizar que al Congreso de Vancouver concurrieron 26.partidos de América Latina y el Caribe, contando los miembros plenos y consultivos y los partidos afines. ${ }^{12}$
\end{abstract}

La amplitud en la caracterización taxativa de los que se encuadraban como partidos socialistas o en todo caso susceptibles -como "afines"- de formar parte de la comunidad partidaria de la IS. se vio facilitada por un aflojamiento en la ortodoxia conceptual, a su vez expresión de un perceptible debilitamiento de los cánones impuestos por la Guerra Fría. El documento fundacional de Francfort era inexorable en su condena al comunismo, como parco en sus referencias a los países de Asia, Africa y América Latina. El texto de la is que sigue en importancia a aquél producido en la reunión de Oslo, Noruega, mantiene el rigor del primer enunciado pero es exultante en cuanto al segundo:

La mayoria de los pueblos de Asia y Africa han conquistado su independencia al iniciarse la década del 60 [...] Por primera vez en la historia, se encuentran liberados de la dominación extranjera, pueblos de todas las regiones del mundo. La is da la bienvenida a los mil millones de habitantes de los nuevos Estados y saluda su participación en el esfuerzo conjunto por obtener justicia, igualdad y paz para toda la humanidad. Pero el colonialismo aún está con vida. Resulta significativo que se atrinchere allí donde no es permitido el movimiento socialista y la misma democracia es reprimida. La Is no ve ninguna justificación moral para la persistencia del colonialismo y lo condena en todas sus formas.

[...] En los últimos diez años, el espíritu humano ha manifestado reiteradamente su aspiración a la libertad y a la dignidad. Muchas dictaduras fueron derribadas en América Latina. ${ }^{13}$

El documento incluye un mayor número de referencias condenatorias del comunismo en comparación con su precedente de Francfort, pero pueden hallarse en él nuevas formulaciones respecto a Asia, Africa y América Latina:

Internacional Socialista en América Latina y el Caribe", p. 269-312 en Centroamérica: crisis y politica internacional, México, CECADE-CIDE, Siglo XXI, 1982.

12 Carlos Morales Abarzúa, La Internacional Socialista. América Latina y el Caribe. México. Editorial Patria Grande. 1981; y edición argentina, Buenos Aires, Michka y Asociados, 1986.

13 Karl-Ludwig Günsche y Klaus Lantermann, Historia de la Internacional Socialista, México, Nueva Imagen/Nueva Sociedad, 1979, p. 291. 
Subsiste el peligro de que los pueblos de los nuevos Estados sean seducidos por las falsas ilusiones del totalitarismo. Las experiencias de nuestro tiempo en Europa, Asia, Africa y América Latina demuestran cuán estéril resulta la negación de la democracia.

Los países latinoamericanos se encuentran liberados, desde hace tiempo, de la dominación colonial, pero comparten algunos problemas con los países en desarrollo. El socialismo democrático se enfrenta, también en ese continente, con problemas como el hambre, el analfabetismo y las epidemias que afectan a millones de personas. ${ }^{14}$

Los estudiosos del proceso de "interconexión" entre la Internacional Socialista y América Latina y el Caribe coinciden en señalar que ella será casi una abstracción durante la mayor parte de la década de 1960 y que sólo surgirá con vigor en la segunda mitad de la década siguiente, a partir de la celebración, en Caracas, Venezuela -mayo de 1976-, de la "Conferencia de dirigentes politicos de Europa y América en pro de la solidaridad democrática internacional". Del encuentro participaron celebridades politicas europeas como Willy Brandt, Bruno Kreisky, Olof Palme, Mario Soares y Felipe González y sus correspondientes de renombre en Hispanoamérica, Rómulo Betancourt, Carlos Andrés Pérez, José Figueres, Víctor Raúl Haya de la Torre y Ricardo Balbín -entre otros-, algunos de los cuales, según Waksman Schinca, no podrían "ser catalogados fácilmente como socialdemócratas, y la mayor parte de ellos rechazaría de modo tajante el rótulo de socialista [...] Por lo demás, las diferencias -de historia, de doctrina, de estructura organizativa, de programación política, de estrategia- entre los partidos latinoamericanos presentes en Caracas son tan enormes que no bastaría para disimularlas la alineación de todos ellos tras las banderas comunes de la socialdemocracia (o cualesquiera otras)". ${ }^{15}$ Más adelante y de un modo francamente escéptico, el mismo comentarista observará:

¿Por qué descubren súbitamente los radicales argentinos o los febreristas paraguayos que es importante conversar con los liberales colombianos o con los "adecos" venezolanos? [...] ¿A qué debe atribuirse este "descubrimiento de América" (de América Latina) por parte de una is hasta ahora fundamentalmente europea y profundamente eurocentrista?

Sin perjuicio de la incidencia de otros factores, parece indudable que el impacto en Europa -y muy especialmente en los partidos socialistas y socialdemócratas- de la tragedia chilena fue sumamente intenso [...] el asesinato de Allende, el sangriento aplastamiento de la experiencia de la Unidad Popular y la instauración de un régimen castrense fascistizante provocaron la repugnancia de todos los socialistas y socialdemócratas europeos. Este sentimiento se ha ido reforzando en el curso de los últimos tres años al ir afirmándose en el vértice austral del continente un verdadero bloque de dictaduras militares de extrema derecha $[\ldots]$

Todo indica que los líderes [...] desde los más avanzados y abiertos (como los suecos, que desde hace años llevan adelante un programa de

${ }^{14} C$. texto completo. "El mundo de hoy desde una perspectiva socialista", declaración del Consejo General de la Internacional Socialista, Oslo, 2-4 de junio de 1962. en Güsche/Lantermann, op. cit., p. 291-301.

${ }^{15}$ Daniel Waksman Schinca, "Mitterrand, la Internacional Socialista y América Latina”, en El Dia, México, 2 de febrero de 1977. 
cooperación técnica con Cuba, por ejemplo) hasta los más conservadores y pronorteamericanos (como los alemanes, cuyos reflejos anticomunistas son fortísimos), concuerdan en la necesidad de conjugar esfuerzos para frenar en América Latina el avance de las dictaduras militares fascistas o fascistizantes $[\ldots]^{16}$

\section{La' "Declaración de Caracas"}

En una crónica posterior, el mismo Waksman Schinca postulaba que "la entrada en la escena política latinoamericana" de los miembros de la is y en especial el encuentro de Caracas "fue una operación concebida y puesta en marcha fundamentalmente por Willy Brandt", aunque no estaba clara la razón de su juego político, puesto que a diferencia de lo que el dirigente del SPD alemán habia logrado en Portugal en favor del Ps encabezado por Mario Soares como alternativa a la toma del poder por parte de la conjunción del Movimiento de las Fuerzas Armadas (MFA) y el PC, no parecía lógico que el SPD "se proponga irrumpir, aquí, ahora, para ayudar a Washington a impedir la toma del poder por los "castrocomunistas' [...]" y, por otra parte, "el incuestionable conservadurismo y filonorteamericanismo" del partido de Brandt "no determina de manera inexorable que éste debe actuar siempre y en todas partes como un socio o agente más o menos directo de los Estados Unidos"; y que entre otros aspectos que requerian una interpretación más matizada de esa irrupción debía tenerse en cuenta el de que "la estrecha comunidad de intereses y estrategias existentes entre los alemanes federales y los norteamericanos no impide, por otra parte, que se generen y desarrollen entre ellos contradicciones secundarias" como en el caso del notorio conflicto estallado a propósito del acuerdo nuclear germano-brasileño. Finalmente, no se debía incurrir

en el error de suponer que la is sea algo así como un "estado mayor conjunto" de la socialdemocracia. De ningún modo: se trata apenas de un ámbito de encuentro y de diálogo para una serie de partidos, prácticamente todos europeos, que tienen un origen común y que sustentan ciertos principios ideológicos, no todos, por cierto, coincidentes. Un "club", como se le ha llamado irónicamente. La is es, en todo caso, un foro y no un aparato. La homogeneidad de los partidos que la integran es por lo demás mucho menor de lo que puede creerse: en muchos sentidos, los socialdemócratas de Palme, los alemanes de Brandt (y de Schmidt) y los socialistas franceses de Mitterrand (y de Rocard) tienen entre sí no mucho menores diferencias, en términos relativos, que las que pueden registrarse entre los radicales de Balbín, los figueristas costarricenses, los adecos o los apristas de Haya [...]. ${ }^{17}$

Ese "ámbito de encuentro y de diálogo", ese "foro", sirvió en todo caso en Caracas de podio político para toda una corriente que a partir de entonces estaría de una u otra manera presente en las peripecias de índole varia que se producirian en Hispanoamérica.

${ }^{16}$ Ibid.

17 Daniel Waksman Schinca, crónica tercera de la serie "Mitterrand, la Internacional Socialista y América Latina", en El Dia, México, 7 de febrero de 1977. 
Con independencia del tono y del fondo de la extensa serie de discursos que se pronunciaron en Caracas, y del hecho irrefutable de que nunca antes se había realizado en América Latina una reunión que congregase a tantos organismos partidarios de este continente y de Europa, rompiéndose así con una valla en la historia del conocimiento y compresión mutuos, esta reunión en Venezuela representó el primero y más importante de los hitos en el proceso de convocatoria y presencia activa de la democracia socialista en la región. Importa por ello reproducir a continuación el texto completo de la "Declaración de Caracas":

Los dirigentes políticos de Europa y América Latina reunidos en Caracas, por invitación de Acción Democrática, han confrontado sus experiencias y programas reconociendo importantes afinidades y principios que los vinculan.

Han reconocido, asimismo, que estos principios pueden servir de base para una acción concertada en favor de la paz, la justicia social, la libertad y la solidaridad internacional, fundadas en el respeto de la soberania de los Estados.

Los movimientos políticos que aquí se han manifestado, tienen diversos origenes y estructuras y proceden, igualmente, de naciones con diferentes grados de desarrollo. Algunos de ellos tienen responsabilidades de gobierno, otros ejercen la oposición democrática, otros luchan contra la dictadura a menudo en el exilio o en la clandestinidad. Todos tienen en común ciertos principios fundamentales:

\section{Condena de toda forma de dictadura}

El rechazo de toda forma de discriminación racial, social o económica, de toda dictadura de derecha o de izquierda; de los imperialismos de cualquier signo y de toda injerencia extranjera en los asuntos que afecten a la soberania de los pueblos u obstruyan su derecho al progreso.

La convicción de que la democracia política, fundada en el respeto de los derechos humanos, individuales y sociales, en la libertad de expresión y en elecciones libres, tanto políticas como sindicales, no es privilegio de los países ricos sino una solución tan necesaria y tan deseable para los pueblos en desarrollo como para los más industrializados.

\section{La Democracia social}

La certidumbre de que la democracia política sólo adquiere autenticidad cuando se complementa con la democracia social y que la libertad sólo se realiza plenamente por la igualdad económica. Esta democracia debe asegurar el mayor grado posible de igualdad en la distribución de la propiedad, del bienestar, del ingreso y del acceso a la cultura y al poder.

La convicción de que no hay solución de validez universal para alcanzar la plenitud democrática. Cada país y cada región deben encontrar su propio camino hacia la libertad y la justicia social, de acuerdo con su realidad y con una creciente solidaridad internacional. No obstante, sostenemos que la justicia social supone en cada pais la promoción efectiva de la igualdad, la regulación de la vida económica por el Estado respetando la iniciativa individual que no contradiga los intereses sociales y populares, la responsabilidad social de la propiedad y la eliminación de los residuos feudales alli donde subsistan. Implica, por otra parte, la superación de todo sistema económico caracterizado por la opresión, la injusta división del trabajo y la sujeción al imperialismo económico, político o ideológico. Comporta también la racionalización y modernización de los órganos de poder. 


\section{Democracia social también en política internacional}

El convencimiento de que la democracia social se demuestra asimismo en las relaciones pacíficas entre los Estados, en el respeto a la autodeterminación de los pueblos y en la voluntad de cooperación internacional, que no debe entenderse como una forma de ayuda caritativa, sino como la necesaria aplicación a nivel internacional de los principios que sostenemos en el interior de nuestros países. Estas relaciones deben estar reguladas por normas precisas en el espíritu de la Carta de los Derechos y Deberes Económicos de los Estados.

Los partidos representados en Caracas, que tienen responsabilidad de gobierno y aquellos que tienen perspectivas razonables de asumirlo, se comprometen a luchar por el cumplimiento y perfeccionamiento de los acuerdos internacionales que en materia económica y social dan forma y sentido a la idea de un nuevo orden económico internacional.

Este nuevo orden ha de regirse por el reconocimiento al derecho que todos los Estados tienen de disponer libremente de sus recursos naturales en su propio beneficio, y a la facultad correlativa de regular las transferencias de capital y tecnología, de obtener precios justos y remunerativos para las materias primas y ventajas preferenciales para los productos manufacturados de los países desarrollados. Implica, finalmente, el rechazo a la injerencia de los gobiernos y consorcios transnacionales en los asuntos internos de otros paises.

\section{Integración regional}

Los procesos de integración regional constituyen uno de los métodos más eficaces para promover el desarrollo y la creación de riqueza, así como para contribuir a una estructura de relaciones económicas más equilibrada entre los pueblos industrializados y los países en desarrollo. Este proceso debe ser impulsado por una firme voluntad política en la que nuestros movimientos y partidos se esfuercen por asegurar una justa distribución de la riqueza y la participación de sus respectivos pueblos en las decisiones que le incumben.

La convicción de que el régimen democrático fundado en el sufragio universal, en la representatividad política y en el equilibrio de poderes, debe complementarse con la adopción de sistemas que aseguren la mayor participación del pueblo trabajador a través de formas de gestión económica y social.

\section{Ayuda a los perseguidos}

Se reconoce que los problemas más graves que afrontan los países en desarrollo son la marginación social y la involución política hacia la dictadura. En consecuencia, los dirigentes aquí reunidos se comprometen a promover la adhesión y respeto de sus gobiernos a los instrumentos internacionales que institucionalizan el asilo y protegen a los desterrados por regímenes dictatoriales, así como la más amplia recepción y atención de los perseguidos políticos, particularmente aquellos sometidos a precarias condiciones, y a defender el derecho de los ciudadanos a salir libremente de sus paises.

\section{Acción concertada}

Los participantes en esta reunión, cuyo propósito no es crear una nueva organización política internacional, encomiendan a un grupo de enlace y de información la tarea de promover nuevos contactos e intercambios.

Los ideales de justicia y solidaridad necesitan la práctica de la acción concertada de nuestros partidos en América Latina y Europa. En 
este sentido, consideran la Reunión de Caracas como un hecho significativo, que debe ser proseguido en otras reuniones a las que habrán de incorporarse, gradualmente, los partidos afines de otras regiones.

Caracas, mayo de $1976^{18}$

\section{De enunciados declarativos a la actuación activa}

Es fácil percibir en este documento una tónica generalizadora y enunciativa, típica de este tipo de reuniones en las que participan partidos y organizaciones de características e ideologia si no del todo contrapuestas, al menos no totalmente coincidentes. Se trató, al parecer, de lograr un consenso sobre puntos básicos que, especialmente en casos de dirigentes de partidos de paises sometidos a dictaduras, no fuesen excesivamente irritantes para éstas de modo que implicaran riesgos de represalias físicas para ellos a su regreso. Por otra parte, la falta de similitud total entre las situaciones de esos países -o la idea que de ellas se hacian los participantes- habría requerido mayores puntualizaciones y posibles confusiones además de un desmedro en la requerida brevedad del texto.

Aun asi, nadie ignoró que el problema fundamental enfocado en la mayor parte de las ponencias y discusiones, estuvo representado por las dictaduras del continente y la tragedia que en gran parte del hemisferio se había abatido sobre sus pueblos, en forma de asesinatos y "desapariciones" masivas de ciudadanos por razones politicosociales, de la prisión de millares de personas y del forzado exilio de muchísimas más. Precisamente países europeos que estaban representados por sus partidos en la reunión de Caracas, no sólo habían demandado respeto por los derechos humanos conculcados -Suecia, Dinamarca, República Federal Alemana, Francia, etc.-, sino que habían dado asilo y cobijo a los así forzados a la emigración de sus patrias. Ese fenómeno jamás antes habia alcanzado tal magnitud, ni por su número, ni por su perdurabilidad, ni por las poblaciones -estadisticamente consideradas- sujetas al control de los ejércitos y fuerzas de seguridad. Junto a esa inédita y multiplicada presencia militarista se produjo otro fenómeno no conocido por sus proporciones y efectos: el de la ferocidad y profundidad de la represión contra toda forma de disidencia u oposición a esa implantación castrense, incluso aquellas que no revistieran carácter de violencia armada.

Los partidos socialistas y sus afines de Europa, eran todos conocedores de esa situación, y algunos de ellos con mayor detalle que otros. La existencia de vastas comunidades de refugiados sudamericanos en España, Francia, Italia y la República Federal Alemana, entre otros países de Europa Occidental, determinaba una mayor posibilidad de conocimiento de esa circunstancia.

Se explica así que aunque la "Declaración de Caracas" contenía algunas referencias poco explícitas sobre la magnitud de la represión, en noviembre de 1976 la is aprobara en Ginebra una "Resolución sobre América Latina" totalmente franca en su condena, con la que se iniciaria la serie que constituiria una constante en los

18 Texto tomado de Günsche y Lantermann, op. cit., p. 303-306. 
documentos de la IS. Además de mencionar expresamente la violación de los derechos humanos en Brasil, Argentina, Chile, Uruguay como institucionalizadores del terrorismo y la tortura, la is deploraba la diseminación de dictaduras militares en América Latina, afirmaba que "estos regímenes represivos han destruido las libertades políticas, culturales y sindicales, así como la libertad de prensa y han encarcelado a sindicalistas y demócratas", finalmente ampliaba el compromiso de la organización con Nicaragua, Guatemala, Haití, República Dominicana, Bolivia y Paraguay.

Con la vista puesta en la próxima asunción de James Carter como presidente de Estados Unidos, se postulaba: "Los Estados Unidos jugarán un papel decisivo en la determinación del futuro de América Latina. Por ello, los partidos miembros de la is deberían hacer valer su influencia para persuadir a la nueva administración de realizar una revisión de su política hacia las dictaduras militares en América Latina, así como de las actividades de las compañias multinacionales [...] La is considera como un paso positivo el levantamiento de las sanciones contra Cuba por la OEA [...], se empeñará en una política orientada a apoyar el desarrollo económico y social de esa región y a lograr una radical redistribución de la riqueza [...] $]^{\prime 19}$ Estas referencias muestran ya la participación de redactores con conocimiento cabal y actualizado de la situación en Hispanoamérica y avances cualitativos en las posiciones respecto de las de Caracas. Era el fruto perceptible del incremento de la presencia de la is en la región, mediante el envío de misiones ad hoc, los contactos más frecuentes entre los dirigentes de ambos lados del Atlántico y la realización de encuentros y seminarios de estudio, investigación y análisis de campo.

Refiere Carlos Morales que a partir de la presencia del Partido Radical de Chile en las reuniones de Helsinki (1971) y Viena (1972), se hizo patente la necesidad de que la is "pusiera una mayor atención en los problemas latinoamericanos y del Caribe" sobre bases orgánicas, tales como las de acordar a la región "una representación en su dirección política" en forma de un organismo de coordinación de los partidos del área. Es así como en el XII Congreso de la IS en Ginebra, durante el cual es elegido por primera vez Willy Brandt, se acuerda designar como vicepresidentes al costarricense Daniel Oduber y al chileno Anselmo Sule, presidente del PR. La designación y la representatividad consiguientes facilitarian sus contactos y pláticas que se traducirian bien pronto en una corriente de información y gestoria de doble vía, además de abrir dentro del continente posibilidades inesperadas de actuación.

Ya Brandt había entrevisto tal apertura, años antes:

[...] en otras partes del mundo también existen partidos socialdemócratas y, sobre todo, partidos y movimientos que, aunque no pertenezcan a la socialdemocracia tal como nosotros la entendemos, están emparentados con ella [...]

En lo que se refiere a la Internacional como órgano que excede el ámbito europeo, yo seria el último en querer debilitar las relaciones con cualquier partido genuinamente socialdemócrata o socialista [...] con aquellos partidos o movimientos que, en cualquier lugar del

${ }^{19}$ Ibid., p. $333-335$ 
mundo, puedan y quieran andar con nosotros una buena parte del camino. Estos partidos existen en América, en Africa e incluso en Asia. De este estrechamiento de lazos se seguirán consecuencias prácticas muy provechosas. ${ }^{20}$

\section{Palme, Kreisky, Brandt}

El sueco Olof Palme, el más familiarizado de los tres con los problemas del Tercer Mundo, y sobre todo con los de los países africanos, ${ }^{21}$ era un permanente impulsor de esa idea: "Nuestro partido fue de los primeros en denunciar y protestar por la intervención de Estados Unidos en la República Dominicana en 1965, y se identificó desde un primer momento con el gobierno de la Unidad Popular chilena. Y considero honroso para Suecia que haya acogido en su suelo a miles de refugiados chilenos y que desde septiembre de 1973 mantenga la misma línea de condena total del régimen de Pinochet." 22 En un registro de años atrás, el mismo Palme escribia en carta a Kreisky y Brandt:

Las conversaciones que he sostenido durante los últimos años con representantes de paises del Tercer Mundo me han demostrado que esos países buscan su propio camino en un mundo como el actual, sometido a una notable polarización de fuerzas. Los paises pequeños tienen miedo del creciente poder de las superpotencias, y esta afirmación también es válida para algunos Estados que se consideran miembros de uno de los dos bloques [...] Quieren encontrar un camino propio. La fuerza y el valor de la socialdemocracia reside en el hecho de que no constituye ninguna amenaza política para estos países. No tenemos la menor intención de decirles cuál es el sistema social que deben adoptar, puesto que sus circunstancias son demasiado distintas de las nuestras. Nunca he podido comprender a quienes intentaban imponer a los países recién descolonizados unas tradiciones europeas que éstos no podian asimilar, pues respondian a circunstancias históricas completamente distintas.

Lo que sí queremos es tener contactos estrechos y abiertos con estos países y debatir con ellos los problemas que se plantean a las fuerzas progresistas en todo el mundo. Nuestra Internacional no puede convertirse en una organización exclusivamente europea [...] Tenemos que encontrar formas responsables y no burocráticas para hacer de la Internacional un foro abierto al debate y a la colaboración de representantes de otras partes del mundo. Para ello, lo esencial no es que estemos todos absolutamente de acuerdo acerca de todas las cuestiones ideológicas, sino que todos tengamos un verdadero sentido de solidaridad internacional. ${ }^{23}$

Casi un año más tarde, el austriaco Kreisky escribía a sus amigos sueco y germano:

${ }^{20}$ Carta de Brandt a Palme y Kreisky, fechada el 17 de septiembre de 1972. Texto total en Willy Brandt, Bruno Kreisky y Olof Palme, La alternativa socialdemócrata. Cartas y conversaciones, Barcelona, Editorial Blume, marzo de 1977 , p. 59-60.

2 Cf. capítulos "Mis orígenes" y "Un socialismo a escala humana", en Olof Palme, La cuestión stieca, Madrid, Editorial Cambio 16, 1977.

i2 Entrevista grabada del autor a Olof Palme en Estocolmo, el 1 de octubre de 1981 .

${ }^{23}$ Carta de Olof Palme del 29 de abril de 1974. Cf. texto completo en Brandt, Kreisky y Palme, La alternativa socialdemócrata, op. cit., p. 123-143. 
Desde la muerte de Allende y el golpe de Estado chileno parece muy dudoso que en América Latina y otras regiones donde la injusticia y el terror coexisten con inmensas riquezas y plutocracias opulentas, las masas estén dispuestas a soportar la prueba de paciencia histórica que supone el esperar un desarrollo democrático por medios pacíficos. En estos países de Asia, Africa y América Latina puede haber movimientos y partidos populares que puedan mantener contactos con los socialdemócratas europeos sin que por ello tengan que ser juzgados con arreglo a los severos criterios de los estatutos de la Internacional. Lo que sí debemos controlar en nuestros contactos internacionales son las posibilidades de desarrollo democrático que existen en cada país. Asimismo, debemos negarnos categóricamente a tener contactos con gobiernos que hagan uso de métodos que vayan en contra de nuestras ideas democráticas fundamentales [...]

[...] en Africa, Asia y América Latina hay paises cuyas condiciones y nivel de desarrollo son muy inferiores a los que se requieren para construir la democracia política. Por otra parte, en esos países la democracia política no representa necesariamente la primera fase de la democratización de la sociedad. Debemos tener en cuenta todos estos factores a la hora de conectar con fuerzas afines a las nuestras en otras partes del mundo $[\ldots]^{24}$

Por último, en un coloquio mantenido por los tres lideres en Viena, Brandt se refirió al "mejor modo de aumentar la cooperación entre los socialdemócratas y las demás fuerzas de parecida ideologia en todo el mundo" y reconoció que en ese sentido "nuestra Internacional se encuentra muy limitada". Consideraba necesario "llegar a una colaboración flexible y no esquemática con fuerzas políticas de otras partes del mundo que tengan puntos de contacto con nuestros partidos aunque partan de otros presupuestos"; luego añadía:

En parte ya se está haciendo algo al respecto, sobre todo en contactos bilaterales. Tomemos el ejemplo de América Central. Allí hay varios países con partidos que están muy próximos a lo que nosotros entendemos por socialismo democrático, pero estos partidos no caben en un marco tan rigido y condicionado por la tradición como es la Internacional Socialista. Por tanto, habría que hallar alguna forma de sostener un cambio de impresiones entre nuestros partidos y los de allí. Deberíamos hablar de cuestiones teóricas fundamentales, pero también de temas eminentemente prácticos [...] Además, necesitamos crear algo así como una "oficina de contactos internacionales" [...] encargada de organizar los intercambios de información y las reuniones con otros partidos [...] Debemos ser lo suficientemente flexibles como para tener contactos con estas fuerzas y encontrar campos de acción comunes a pesar de las posibles divergencias.

Medio año después de haberse hecho cargo de la presidencia de la IS, durante un congreso en Oslo, Brandt se mostró optimista: "Me parece que estamos contribuyendo a que la Internacional cobre nueva vida." Una condición indispensable era que él y otros miembros coincidieran en "la superación del eurocentrismo, fenómeno comprensible por la historia de la Is, pero causa de su decadencia en la década de 1960". En la reunión que el Buró realizó en Madrid en 1977, fue aprobada una moción para "establecer un

it Carta de Bruno Kreisky a Palme y Brandt, fechada el is de abril de 1975. Texto completo en Brandt, Kreisky y Palme, op. cit., p. 155-163. 
Comité de América Latina de la is". Hasta entonces y por la naturaleza misma del problema suscitado en Chile en septiembre de 1973, gran parte de los esfuerzos de la organización se centraron en la situación de aquel país.

Sin descuidar la atención en esa dirección, se decidió ampliar el espectro de preocupación y análisis regional y a tal efecto, en marzo de 1978, una misión presidida por el portugués Mario Soares visitó México, Venezuela, Costa Rica, República Dominicana y Jamaica y produjo sendos informes, que complementó con otros sobre países no visitados, Argentina, Brasil, Chile, Curaçao y Aruba, El Salvador, Guatemala, Nicaragua, Panamá, Paraguay, Perú, Puerto Rico y Uruguay. El Nuevo Mundo aparecía como la región que se convertía en eje de interés, por la percepción de Brandt de que alli residen más fuerzas politicas cercanas y afines a la is que en cualquier otra área del Tercer Mundo. En noviembre de 1978 , en la ya citada reunión celebrada en Vancouver, Canadá, se resolvió crear el Comité de la Internacional Socialista para América Latina y el Caribe, en medio de la exultación que producian las noticias sobre el generalizado levantamiento popular en Nicaragua y las expectativas de una inminente caída del régimen somocista. La declaración final de la reunión precisamente alude a esa eventualidad.

El Comité de la is para América Latina y el Caribe celebró su primera reunión en la ciudad de Santo Domingo -24-25 de marzo de 1980-, seguida los días 26 y 27 por una Conferencia Regional de la is que fue la primera en su género y de la que participaron miembros plenos y consultivos, numerosos partidos y movimientos "amigos y afines" e invitados personales. La reunión se desarrolló en el marco luctuoso del asesinato del arzobispo de San Salvador, Oscar Arnulfo Romero, y la "Declaración de Santo Domingo" fue un extenso documento en el que prácticamente se abordó la problemática del Continente, así como la de otras regiones del Tercer Mundo.

Uno de los observadores escribió que hasta la asamblea de Santo Domingo, la is había estado sobre todo "explorando el terreno, ampliando relaciones, aunando alianzas, ensayando tácticas políticas", pero que a partir de esa reunión tenía que entrar en "una etapa de definiciones y jugadas más comprometedoras" y afrontar, entre otros difíciles desafíos, el que planteaban países como El Salvador, donde ya la guerra civil era indetenible. ${ }^{25}$

\section{Desde Santo Domingo}

Eștaba en el aire mucho más de lo que nadie deseaba aventurarse a explicitar. El presidente James Carter, lanzado a la carrera de la reelección presidencial, se inclinaba a disputar a su rival y republicano Ronald Reagan el favor de los votantes, desde posiciones cada vez más conservadoras y derechizadas. El discurso del candidato Reagan apelaba a la derogación del síndrome de Vietnam, a la recuperación de Estados Unidos como primera potencia mundial indiscutible, a la reversión (roll-back) de lo perdido su-

\footnotetext{
is Daniel Waksman Schinca, "De Caracas a Santo Domingo: cuatro años de
} intensa actividad. La is en América Latina", El Dia, México, 9 de abril de 1980. 
puestamente por debilidad del Partido Demócrata en el poder, en lo cual incluía situaciones de "derrota" tales como la presencia de los sandinistas en el gobierno de Nicaragua y del New Jewel Movement en Granada, las explosiones de insurgencia en El Salvador y Guatemala y hasta la firma misma del tratado Carter-Torrijos, que había establecido un nuevo status en la Zona del Canal que sectores de la nueva derecha norteamericana, como los que se expresaban en el conocido Documento de Santa Fe, consideraban lesivos para los intereses de la seguridad de Estados Unidos.

La solidaridad de la is para con la experiencia revolucionaria sandinista no ofreció casi fisuras por parte de los países europeos que a través de la ayuda material y moral respaldaron la lucha armada y a continuación las tareas iniciales de reconstrucción. Análoga tesitura observaron en la primera fase de la insurgencia salvadoreña, a pesar de que se consideraba un problema mucho más complejo. Tampoco faltó la simpatia para el partido y el gobierno granadino de Maurice Bishop.

Esa atmósfera comenzó a cambiar imperceptiblemente en la segunda mitad de 1980. Afganistán había sido invadido por tropas soviéticas, Carter habia retrogradado su relación con Cuba desde la primera buena voluntad de 1977 , la conflictiva situación con Irán a resultas de la retención de rehenes norteamericanos en Teherán provocaba un sentimiento de humillada frustración en la opinión pública norteamericana y en la propaganda electoral republicana se presentaba a Centroamérica y el Caribe como caídos en brazos del "comunismo". Era ya una segunda Guerra Fría, recalentada por amplios motivos de disgusto interno derivados de la pésima administración de Carter. Este perdió en las elecciones de noviembre de 1980 y el electo Ronald Reagan asumía su mandato el 20 de enero de 1981 .

Apenas un mes después de su asunción, el Departamento de Estado daba a conocer un estruendoso "Libro Blanco sobre El Salvador", en el que, con base en una porción de documentos proporcionados por la fuerza armada salvadoreña (a los que, según se denunció más tarde, se habian extrapolado falsificaciones de forma y de fondo), material que fue presentado como prueba irrefutable de que la guerra civil cuscatleca, en esos momentos ya un hecho irreversible, era consecuencia de la ayuda militar prestada por la Unión Soviética y otros países del campo socialista a través de Cuba, con utilización del territorio de Nicaragua como vía del trasiego.

A partir de ese golpe de efecto internacional se marca la línea divisoria entre la marginación "neutralista" que dedicó Carter a Centroamérica, y la asignación de carácter prioritario que le acordaría Reagan y de la que hasta ahora no se ha apeado. La ofensiva escogió el blanco debido a la percepción del secretario de Estado, Alexander M. Haig, de que dentro del mismo año se obtendría una victoria estratégica y política sobre la insurgencia salvadoreña y de paso sobre el gobierno sandinista. En el primer paso se confiaba en el poder bélico superior castrense; en el segundo, en el efecto de la suma de presiones políticas, económicas y diplomáticas, con el apoyo de aliados internos y la compulsión armada que se ejerceria - a cargo de bandas mercenarias y de exsomocistasdesde el vecino territorio de Honduras. 
La suma de todos los factores que puso en juego la administración Reagan no iba a demorar en reflejarse en las posiciones de algunos partidos de la IS. El primero en expresarse en esa dirección fue el PLN costarricense, mediante declaraciones de antagonismo hacia la insurgencia salvadoreña representada por el FDR-FMLN. La campaña electoral de 1981 consagró a Luis Alberto Monge como candidato y éste, en pos del triunfo, se valió de la tónica provinciana tradicional de hacer del presidente saliente, Rodrigo Carazo, la causa de todos los males económicos y sociales que agobiaban al país.

La circunstancia de que Carazo habia consentido que Costa Rica fuese ruta de tránsito para las armas que el presidente venezolano Carlos A. Pérez y el panameño general Omar Torrijos -entre otros- habian despachado a los combatientes sandinistas, situó a la revolución nicaragüense en elemento de imputaciones mutuas de los partidos mayoritarios costarricenses en pugna. Por extensión, y al calor de las excitativas de la prensa escrita y electrónica local, quizás la más impúdicamente reaccionaria y desinformadora del continente, Nicaragua pasó a ser el eje del debate electoral, convertida en chivo expiatorio de los problemas de Costa Rica. Extemporánea y gratuitamente, tanto Monge como su contrincante competian desaforadamente con sus invectivas, agravios e imputaciones de todo jaez al vecino país. Lograda la victoria, Monge y el PLN aminoraron por innecesaria la cantidad y frecuencia de sus diatribas, si bien manteniendo las baterias dispuestas para eventuales andanadas.

En noviembre de 1981, cuando ya la participación de Estados Unidos en la guerra civil salvadoreña era proclamada sin ambages por Reagan, éste autorizó secretamente al Consejo de Seguridad Nacional el primer financiamiento a los contrarrevolucionarios nicaragüenses mediante una asignación de casi 20 millones de dólares destinados a preparar una fuerza armada de 500 mercenarios que supuestamente debía hostigar y/o derrocar al gobierno sandinista. ${ }^{26}$ A esta "Guerra de Reagan" hasta ahora, a seis años de distancia, no oficialmente declarada, se le agregaron todos los ingredientes derivados del carácter prioritario que le acordó la administración y a los que sólo faltarian los de una invasión directa de las fuerzas armadas de Estados Unidos de acuerdo con el modelo de la intervención armada en Granada -octubre de 1983para completar su parábola.

Honduras fue la primera plataforma de lanzamiento de tal agresión encubierta, a la vez que refugio, santuario y campo de adiestramiento de los mercenarios. Costa Rica fue la segunda, si bien a escala más reducida y con mayores reticencias y pudores de su gobernante, el resbaladizo Monge, que el 17 de noviembre lanza urbi et orbi su solemne proclama de neutralidad "activa, perpetua y no armada" que si sirvió para muchos discursos y alegatos de inocencia y ajenidad en relación con los ataques armados de que era victima Nicaragua desde territorio costarricense, no los impidió.

\footnotetext{
26 Mediante la "National Security Decision Directive-17" (NSDD-17) del 16 de noviembre de 1981 . Cf. para más detalles la obra de este autor, Reagan entre El Salvador y las Malvinas, México, Mex-Sur Editores, 1982.
} 
En septiembre de 1986 y ya presentada por Nicaragua ante la Corte Internacional de Justicia de La Haya la demanda contra Costa Rica -y también contra Honduras-en razón del cúmulo de tales agresiones solapadas contra su territorio, el ministro de Gobernación, Hernán Garrón Salazar, admitió en rueda de prensa que fue el gobierno de Monge el que en 1985 autorizó a Estados Unidos la construcción de un aeródromo clandestino en la provincia de Guanacaste, a escasos kilómetros de la frontera, para su utilización en función bélica por los contrarrevolucionarios vinculados con la CIA y el Pentágono. ${ }^{27}$ El estallido del escándalo Iráncontras, la investigación emprendida por el senador demócrata John Kerry ${ }^{28}$ y las conclusiones de la Comisión Tower $^{29}$ no sólo ratificaron ese papel cómplice del gobierno de Monge en la agresión contra su vecino, sino que añadieron datos impresionantes acerca de la magnitud de esa complacencia servil.

La presentación en La Haya del gobierno de Managua desató del todo los ya excesivos ataques de la prensa costarricense, del gobierno de Oscar Arias Sánchez y del partido gobernante, el PLN, miembro de la IS. Su secretario general, Rolando Araya Monge, burócrata del partido cuya mayor virtud militante es la de ser sobrino del expresidente y estar ya lanzado en la carrera por la sucesión presidencial de Arias, aprovechó todos los foros internacionales subsiguientes a aquella presentación jurídicolegal (incluyendo las reuniones y seminarios de la is) para impugnar y descalificar su asistencia - a simple título de observador- del Frente Sandinista de Liberación Nacional (FSLN), fundando su posición en que es un partido "totalitario".

Con antelación, durante la campaña electoral de 1985, el candidato Arias Sánchez había agredido sistemáticamente a la revolución nicaragüense y a sus gobernantes y en algún momento llegó hasta a indicar que si el PLN triunfaba en los comicios de febrero de 1986 , se retiraría de la is como expresión de protesta por el apoyo que la organización brindaba a Managua y por aceptar que el FSLN participara de sus distintos cónclaves. Si bien es cierto que no llevó a la práctica ese anuncio, no lo es menos que desde el primer momento de su gestión presidencial, Arias Sánchez se destacó por la virulencia y el poco respeto de sus discursos hacia $\mathrm{Ni}$ caragua y sus dirigentes sandinistas. Más aún, a despecho de la reconocida honestidad con que en el pais vecino se celebraron las elecciones del 4 de noviembre de 1984 y del detalle de que entre

\footnotetext{
27 Esa admisión la formuló Garrón a principios de septiembre de 1986, añadiendo que el aeródromo ya estaba ocupado por fuerzas gubernamentales y su utilización prohibida. Cf. The Tico Times del 16 de enero de 1987, San José, Costa Rica, en donde Monge explica por qué consintió ese allanamiento foráneo de la soberania nacional; o la traducción de esa entrevista de María Elena Carvajal en nuestra crónica "El aeródromo de la CIA en Costa Rica que Monge autorizó", en $E I$ Dia. México, 2 de marzo de 1987.

28 Dada a conocer el 15 de octubre de 1986 , en sus conclusiones iniciales, por el propio Kerry, a manera de adelanto y que mencionan la "conexión tica" del tráfico de drogas de los contrarrevolucionarios.

${ }^{29} C f$. su texto, conocido como Informe Tower, en el libro que la Comisión editó con el titulo de Report of the President's Special Review Board, y también en una amplia condensación, "Excerpts From the Tower Commission's Report", en The New' York Times, 27 de febrero de 1987, p. 12-18. Además, The Tower Commission Report. The New York Times and Bantam Books, Febrero 1987.
} 
quienes las consideraron democráticas y correctas, figuraba la misma Internacional Socialista, ${ }^{30}$ Arias Sánchez las desconoció como tales, las impugnó como fraudulentas siguiendo en esto la táctica reaganiana, y se dedicó a demandar "nuevas y democráticas" elecciones como parte de su programa de "pacificación" de Centroamérica.

\section{La is y Nicaragua}

La ofensiva global contra Nicaragua resuelta por la administración Reagan desde noviembre de 1981, tuvo, pues, su correlato en el seno de la Is. En forma paulatina y con acre tono creciente pero acorde con los sucesivos pasos de Washington, el PLN costarricense y Acción Democrática $(\mathrm{AD})$ venezolana -entre otros de América Latina- se sumaron a la no adhesión, a la censura, al hostigamiento y por último a la agresión a la revolución sandinista y de modo paralelo a la revolución salvadoreña, no obstante estar representado ante la is, con carácter de miembro pleno, el Movimiento Nacional Revolucionario (MNR), integrante de la coalición FMLN-FDR.

Los partidos socialdemócratas y socialistas de Europa pasaron de una fase de simpatía y expectativa favorable, a otra de desconfianza y por último de franca hostilidad. No todos, claro está, pero sí algunos de cierta importancia, como el PS de Italia y su similar de Portugal. En otros la nota predominante es la pendular cuando no la ambigüedad o la "discreta repulsa" al gobierno de Managua. Sectores del germano SPD o del PSOE le censuran o reprochan sus elementales medidas de defensa frente a la agresión externa e interna pero, sobre todo, su presunto incumplimiento de un supuesto compromiso asumido por dirigentes sandinistas ante la Organización de Estados Americanos (OEA) en vísperas de su victoria -junio de 1979-, "incumplimiento" del que es principal reclamante el equipo de Reagan, que asevera que aquéllos "traicionaron" la palabra empeñada en materia de pluralismo político y libertades democráticas, economía mixta y no alineamiento.

Fuera de que resalta la incongruencia de que sea precisamente la administración Reagan la que se constituye en albacea y garante de ese supuesto compromiso, quienes exigen su cumplimiento desdeñan las evidencias de que de un modo general tales asunciones unilaterales de los sandinistas en plena lucha antisomocista se cumplen y que si hay casos de excepción ellos se deben precisamente a que la agresión armada y el bloqueo económico y financiero dispuesto por Washington no consienten otras alternativas para el frente interno y las exigencias del afianzamiento de la revolución.

$\mathrm{Y}$ puesto que la revolución tiene, como primer deber, su subsistencia, tampoco seria reprochable que se le exijan las normas deseables para un estado de paz y normalidad, que no haya censura de prensa $o$ que no se clausure provisionalmente a periódicos ob-

\footnotetext{
${ }^{30}$ Véase el Informe Stoltenberg redactado por la comisión de la is que viajó al efecto a Nicaragua; también, entre otros, el informe de Lord Chitnis, dirigente del Partido Liberal británico; y el de la Latin American Studies Association (LASA) de Estados Unidos, "The Electoral Process in Nicaragua", noviembre 19, 1984.
} 
jetivamente contrarrevolucionarios como La Prensa de Managua o a la Radio Católica, o que no se apele al arbitrio de expulsar del país a un obispo sedicioso con agravantes, Pablo Antonio Vega, o que no se impida el reingreso de otro sacerdote no menos provocador y subversivo como Bismarck Carballo. Y ello, otra vez, a pesar de lo discutible que resulta que una expresión de deseos vertida en circunstancias de excepción como las de junio de 1979, sea transformada en un "compromiso legal" del que se exijan cuentas a un gobierno establecido, y menos aún en el marco del derecho internacional como lo puntualizó acertadamente la Corte Internacional de Justicia de La Haya. ${ }^{31}$

Si en Iberoamérica son puntas de lanza partidarista contra la revolución nicaragüense el PLN de Costa Rica y la AD venezolana, no ocurre lo mismo con el partido peruano APRA, cuyo titular, el presidente Alán García, viajó expresamente a Nicaragua el día que entró en vigor la Constitución de Nicaragua, el 9 de enero de 1987, a modo de ratificar su adhesión y la de su partido al proceso revolucionario sandinista. Junto con el mexicano José López Portillo y el entonces premier sueco Olof Palme, el mandatario peruano fue de los pocos que violaron el tabú de omitir de sus viajes a la proscrita -por la administración Reagan- Nicaragua.

Otro argumento grato a Washington es el que convierte a Nicaragua en títere o surrogate de la Unión Soviética y/o de Cuba, o, en todo caso, el señalar su creciente dependencia respecto del bloque soviético, en el marco de la confrontación Este-Oeste. El conjunto de ese tipo de argumentaciones da pretexto a ciertos partidos y agrupaciones de la is en Europa para distanciarse de Nicaragua, para restarle apoyo económico, político y moral, y, en última instancia, para ponerse al servicio de la propaganda y la guerra psicológica de la administración Reagan. Esa actitud y severidad no se compadece con la blandura y la tibieza con que esos partidos reaccionaron frente a actos de piratería internacional tan flagrantes como el perpetrado por los Estados Unidos contra Granada, pese a ser miembro pleno de la Is su New Jewel Movement, o frente a la continuada guerra no declarada de Estados Unidos contra Nicaragua, caso en el que resulta más simple descargar las culpas sobre la nación agredida antes que sobre la potencia agresora.

\section{El peso moral de la is}

Este autor participó, como invitado observador o como periodista, en varios congresos y reuniones de la is en Europa y América Latina; entre estas últimas en la celebrada en Santo Domingo en 1980. Pero de entre los incidentes de los que fue testigo y guarda memoria especial, mencionaré el producido en la reunión de Basilea, Suiza, a principios de noviembre de 1982, cuando fue presentado un proyecto de censura a Israel por los tremendos sucesos de Sabra y Chatila, en el Líbano, ocurridos muy poco antes. La moción fue rebatida e impugnada por dos partidos socialdemó-

${ }^{3} C f$. el texto de ese rechazo juridico en Nicaragua v. The United States of America. Judgement of the International Court of Justice, La Haya, 27 de junio de 1986, p. 124-125, donde se declara que en derecho internacional no hay otras leyes que las que un Estado haya concertado por tratados o acuerdos especificos. 
cratas israelíes y, en determinado momento, el tono del debate se hizo tan intenso, que el delegado Shimon Peres llegó al extremo de hacer algo más que sugerir que quienes proponian la censura o la respaldaban -entre ellos el sueco Pierre Schori, el estadunidense Michael Harrington y el suizo Jean Ziegler- eran antisemitas.

Fue quizás la única ocasión en que a este autor le tocó presenciar una descomunal batahola en una reunión de la Is. Los imputados demandaron el retiro de este torpe agravio y las consiguientes excusas, so pena de abandono inmediato de las sesiones. La intervención del presidente Willy Brandt logró llegar hasta la satisfacción y las disculpas; Peres dijo que no quiso decir lo que dijo o que fue mal interpretado. De todas maneras lo que importaba, una cabal condena a los autores y coautores de la horrenda matanza, no se produjo y en su lugar hubo una declaración en lenguaje propio de caballeros "perturbados" por los sucesos, que en el mundo entero fueron considerados "crímenes de lesa humanidad" y a los cuales Noam Chomsky se refirió como actos de wholesale terrorism, "terrorismo al por mayor" o "a gran escala".

El escritor y sociólogo suizo Ziegler, había escrito semanas antes de la reunión de Basilea ( 3 al 5 de noviembre de 1982):"La Internacional Socialista no es ni una gran potencia militar ni una sociedad capitalista multinacional, capaz de intervenir unilateralmente en las relaciones internacionales y de imponer allí su voluntad. Su única fuerza es su credibilidad, el peso moral que se vincula con su política, la adhesión espontánea que obtienen los principios que defiende [...] La IS es una organización compleja, atravesada por contradicciones profundas, heredera de una historia rica y tumultuosa. En su seno coexisten lo peor y lo mejor, el cinismo y la esperanza." 32

Lo mejor y lo peor. Cinismo y esperanza. Categorizaciones plenas de escepticismo aplicadas al modus vivendi de la is por un socialista militante y convencido, cuyos principios éticos se sienten mellados por las contrariedades y decepciones derivadas de la regular aplicación de la realpolitik al juego de las realidades cotidianas, generalmente obscenas y fastidiosas. Desde fuera, por otra parte, son incoherencias y contradicciones, ambigüedades y defecciones en la aplicación concreta de aquel credo, que refuerzan las censuras fundadas en ubicaciones radicalizadas, en especial desde la izquierda, facilitadas objetivamente cada vez que hace eclosión algún tipo de situación límite, que exige definiciones públicas de la IS. Esto es notorio sobre todo en el discurso contestatario y disidente europeo -que no es el que frecuentan los lectores y militantes de la izquierda latinoamericana- el que persiste en señalar peyorativamente a la is como una reedición más del socialismo bernsteiniano y conviviente de principios de siglo. Las incongruencias y complejidades de ese movimiento que sólo en parte es ideológicamente homogéneo, demandan también ese tributo a la credibilidad.

Ziegler se congratuló de que en Vancouver se hubiese materializado "la apertura al Tercer Mundo", rompiéndose "por fin el eurocentrismo de la Internacional", así como porque en el Congreso

32 Jean Ziegler, "Crisis en la Internacional Socialista", en Le Monde Diplomatique en Español, México, núm. 46, octubre de 1982, p. 2. 
de 1980 en Madrid "se tomaran medidas concretas para asegurar un apoyo efectivo -diplomático, financiero-, a movimientos de liberación nacional, a movimientos de resistencia en América Latina (ayuda para la Nicaragua sandinista, para el FMLN-FDR de El Salvador, para el movimiento socialista de Guatemala, apoyo a la resistencia chilena...)" en una alianza de voluntades a la que consideraba "un hecho realmente nuevo, de una importancia histórica capital".

¿Qué pasó con tanta buena voluntad junta de la is en Europa? ¿De qué modo se cumplieron los acuerdos y compromisos de los partidos tradicionales y poderosos del Viejo Mundo con los desvalidos y retrogradados pueblos de Iberoamérica y, en general, del Tercer Mundo?

Si comenzáramos con la entrañable España, deberíamos mencionar nuestra enorme sorpresa de una visita en 1986, al comprobar que la misma expresión "Tercer Mundo" tiene una connotación despreciable y peyorativa en la opinión pública, tanto como la que tenía la expresión "sudacas" aplicada a los sudamericanos y centroamericanos forzados a huir de sus patrias por la persecución políticosocial de las dictaduras militares y de sus "guerras sucias", tanto como por los rigores del desempleo. De pronto, la España que no termina de ser el apéndice de Africa como lo advertía Miguel de Unamuno, descubre por su ingreso al Mercado Común Europeo que es un país "occidental" como el que más pero más cristiano aún, si cabe; de donde deduce que dejó los hábitos mendicantes tercermundistas que sólo sirven ahora para cubrir los ateridos y escuetos huesos de los iberoamericanos, africanos y asiáticos. Y para poner distancia con respecto a su condición desmedrada de apenas ayer, recurren al lamentable arbitrio de menospreciar a sus hermanos en condición y dependencia.

No seria justo afirmar que ésta sea la tesitura de todo el PSOE, pero sí de una buena cantidad de sus dirigentes, mentores y sustentadores. Trasladada esa visión novoeurocéntrica a las percepciones de política exterior, ¿qué ha quedado de la Comisión de Apoyo a la Revolución de Nicaragua, creada por aclamación en el Congreso de la is celebrado en Madrid en 1980 y del cual se designó presidente, también por aclamación, al por entonces dirigente de la oposición Felipe González? ¿Implica defenderla el estar enviando desde entonces a Managua, cada muchos meses, a alguna funcionaria de tercera fila del partido, dizque experta en asuntos iberoamericanos, para que eche un vistazo, platique con algunos funcionarios sandinistas con la misma "imparcialidad" con que otros de su mismo partido se sientan a una misma mesa a dialogar con dirigentes contras y luego regresan a Madrid a deplorar en privado o en público la falta de "libertades democrăticas" hallada durante su veloz recorrido de un día por la capital de Nicaragua? ${ }^{33}$

${ }^{3,3}$ En febrero de 1986, una comisión "especial" de la is de la que eran miembros un delgado del PSOE. el venezolano Carlos Andrés Pérez y el germano Hans-Jürgen Wischnewski entre otros, recorrió en tiempo record los paises centroamericanos. El día previo a su estadia de 24 horas en Managua, se reunieron en San José de Costa Rica con una delegación local de contras. Concluida su misión de estudio, viajaron a Washington, donde para su decepción los atendió una funcionaria de tercera del Departamento de Estado. Horas más tarde, en rueda de prensa en Madrid, censu- 
Lo mejor y lo peor. Cinismo y esperanza. ¿De qué modo ayuda al pueblo y a las naciones nicaragüense y salvadoreña el PS francés compelido a una incestuosa "cohabitación" con la derecha de Jacques Chirac y a guardar silencio ante la provocación y el insulto inferidos al gobierno legal de Managua por su reaganiano canciller Didier Bariani en febrero de 1987, cuya irresponsabilidad y conducta de patán fueron altiva y dignamente enfrentadas por el vicepresidente Sergio Ramírez, que se negó a recibirlo y de hecho le dio con la puerta en las narices?

¿De qué modo respaldan a la hambreada y acosada Nicaragua los socialistas de Italia, o los socialismos nórdicos -exceptuado, claro está, el de la noble y consecuente Suecia- o el del germano SPD fuera del respaldo personal y moral de Willy Brandt, generalmente más dispuestos a mirar la paja de la interdicción y la censura provisionales a medios de prensa servidores de la guerra de Reagan o las medidas contra sacerdotes facciosos y provocadores, antes que a observar la viga del bloqueo y la agresión yanquis? ¿Por qué puede ser entendible y "lógico" que Felipe González y el PSOE aleguen que no pueden indisponerse con Estados Unidos ni con la OTAN en razón de sus necesidades vinculadas al Mercado Común Europeo y, en cambio, no pueda ser "lógico" y entendible que las medidas de excepción dispuestas por Nicaragua frente a la guerra de Reagan son justas, patrióticas y razonables, y no producto de supuestas orientaciones "totalitarias" y "antidemocráticas”? ¿Por qué los altibajos e incoherencias en las posiciones del SPD y su vergonzante y debilitadísimo apoyo a Nicaragua?

\section{Paternalizada Iberoamérica}

Palos porque bogas y palos porque no bogas, los partidos europeos reprochan a Nicaragua que acepte la ayuda que le brindan los países del campo socialista u otros como Libia, ayuda que ellos mismos comenzaron a retacear para finalizar negándola del todo ${ }^{34}$ a partir de su percepción de que los sandinistas no son lo suficientemente "comprensivos", "maleables", "flexibles" y en última instancia agradecidos a los consejos y colaboraciones varias que ellos desprendidamente brindan $\mathrm{u}$ ofrecen.

La desequilibrada visión eurocentrista sigue privando e incide sobre otros temas criticos de América Latina y el Caribe, favorecida además por la ignorancia que de la historia y del presente de nuestra América padecen la mayor parte de los dirigentes europeos (en la reunión de Basilea, el socialdemócrata Pietro Longo afirmó que el de Puerto Rico era un asunto tan interno de Estados Unidos como podria serlo una escisión del Estado de Alaska o un

raron al gobierno sandinista por la "falta de democracia" en el pais. Para las elecciones de 1984 y a pesar de la expresa invitación del gobierno sandinista, el PSOE se negó a enviar observadores a Nicaragua, cosa que en cambio sí hizo la centroderechista AP. cuyo enviado retornó a España alabando la honestidad de los comicios. Para esas y otras inconsecuencias, consúltese Marcos Roitman, La política del PSOE en América Latina, Madrid, Editorial Revolución, 1985.

${ }_{34}$ Durante el gobierno socialdemócrata de Helmut Schmidt se acordaron $40 \mathrm{mi}-$ llones de marcos de ayuda a Nicaragua, sin que hasta el término de su mandato le fuesen entregados. Esa suma sigue hasta hoy retenida por expresa resolución del régimen democristiano de Helmut Kohl. 
conflicto racial en Carolina del Norte), o distorsionada por el traslado mecánico de los ingredientes geopolíticos y estratégicos de la confrontación Este-Oeste a la peripecia peculiar, localizada nacional o regionalmente, de experiencias revolucionarias centroamericanas del tipo de la nicaragüense o la salvadoreña.

No cabe dudar que para la lucha armada del sandinismo fue importante el respaldo moral y hasta material de la is pero es igualmente cierto que en tanto duró la fase bélica los partidos y dirigentes europeos observaron una prudente actitud de abstinencia política -de la que no estuvieron ausentes ciertas proclividades y simpatías preferenciales- en tanto los protagonistas mismos de la insurrección decidian en materias que les eran propias.

Respecto de la dictadura somocista en Nicaragua, el SPD habia conservado un silencio de decenios. En el gobierno de la República Federal Alemana, desde 1969 había continuado concediendo ayuda económica, reembolsable o no, a la dictadura, igual que los anteriores gobiernos democristianos. Sólo en pleno auge de la insurrección popular, en septiembre de 1978, se produjeron las primeras declaraciones de la IS y el SPD en apoyo del pueblo nicaragüense. El apoyo de la is no iba dirigido, sin embargo, al FSLN sino a la Unión Democrática de Liberación (UDEL) y al Frente Amplio Opositor (FAO), y a la reunión de la is en Lisboa a fines de septiembre de 1978, se habia invitado, significativamente, a Donald Castillo como representante del FAO y no a una delegación sandinista. ${ }^{35}$ Si estuvo presente Ernesto Cardenal, pero sólo a título personal.

El XIV Congreso de la IS, celebrado a principios de noviembre de 1978 en Vancouver, Canadá, ya reflejó člaramente un cambio de actitud de la organización debido al rápido desarrollo del proceso revolucionario nicaragũense. Con la salida del Grupo de los Doce del FAO poco antes, este último agrupamiento había perdido importancia, mientras que la amplitud de la lucha insurreccional estaba abriendo perspectivas reales de un triunfo del sandinismo a mediano plazo. Consecuentemente, la is invitó a Ernesto Cardenal, pero en esta ocasión como delegado oficial del FSLN. Además de varias declaraciones de apoyo, se le prometió a Ernesto Cardenal que la is iba a entregar, de aquí en adelante, la cantidad de 50000 dólares mensuales al FSLN para ayuda humanitaria, ayuda que, sin embargo, se materializó solamente una vez. ${ }^{36}$

A continuación, la is y el SPD comenzaron a prestar un respaldo solidario, que se expresó fundamentalmente en la oferta de foros y medios de comunicación internacionales para difundir la lucha del pueblo nicaragüense, el FSLN [...] sin embargo, durante todo ese periodo el gobierno socialdemócrata de la RFA no rompió las relaciones diplomáticas con el régimen somocista, siguió concediendo apoyo económico a la dictadura e incluso aprobó un empréstito por valor de 66 millones de dólares, concedido al régimen somocista en mayo de 1979 , o sea dos meses antes de la caida de éste, a través del Fondo Monetario Internacional.

[...] Después del triunfo de la revolución sandinista, sin embargo, la

${ }^{35}$ Se trata del mismo que acompañó en su defección al cabecilla Edén Pastora, actuando como asesor suyo en el santuario contra de Costa Rica y posteriormente en Estados Unidos.

${ }^{36}$ Theo Rathgeber, "Sozialdemokratische Solidarität mit Nicaragua und El Salvador", en FDCL (ed.), Sozialdemokratie und Lateinamerika, Berlín, 1982. Citado en "La Internacional Socialista en Centroamérica", prólogo a la publicación del mismo título, El Parcial, Hamburgo, RFA. núm. 11, diciembre de 1983. 
IS reiteró su pleno respaldo al FSLN y se apresuró a enviar una delegación a Nicaragua, encabezada por Mario Soares [...] Como resultado de su misión, Soares recomendó y prometió una amplia ayuda inmediata de la IS para la reconstrucción del país; pero esta ayuda no se concedió, ni en la cantidad requerida ni con la rapidez adecuada. El gobierno socialdemócrata alemán, por ejemplo, "que había anunciado una cantidad generosa en ayuda inmediata, por valor de 20 millones de marcos sólo había entregado casi 3 millones a principios de octubre de 1979 , mientras que frente a la catástrofe del terremoto de 1972, la ayuda inmediata de la.RFA a la dictadura somocista fue de 35 millones de marcos entregados con relativa rapidez". ${ }^{37}$

De aquí en adelante quedaba claro que ni la is y aún mucho menos el gobierno alemán, iban a dar la prometida ayuda "sin condicionamientos políticos ni ideológicos". Antes por el contrario, el gobierno alemán asumió una actitud vacilante en relación a la reconstrucción económica de Nicaragua, equivalente en la práctica a una tentativa de estrangulamiento de un desarrollo autónomo. De tal manera que en el año 1980, en el cual el gobierno socialdemócrata entregó al régimen fascista de Turquia 650 millones de marcos en ayuda económica y 130 millones en ayuda militar; Nicaragua recibió la suma comparativamente modesta de 100 millones de marcos y, para colmo, un cierto porcentaje de dicha cantidad dirigido directamente hacia las empresas privadas para eludir el control por un gobierno sospechoso. ${ }^{38}$ En contraste con la escasa ayuda material que la is otorgó a la revolución sandinista, hubo una abundancia de manifestaciones verbales de solidaridad que indiscutiblemente tuvieron un efecto benéfico frente a la cada vez más fuerte campaña diplomática, económica y militar de los Estados Unidos contra la revolución nicaragüense. ${ }^{39}$ Pero también este apoyo verbal estaba lejos de ser unánime entre los partidos miembros de la is $[. . .]^{40}$

Durante la primera fase del entusiasmo inicial o del "deslumbramiento" de la IS por lo que sucedia en América Central, la fraternidad y la adhesión no estuvieron condicionados por supuestos de ideología o de oportunismo político, lo cual resultaba más significativo por la circunstancia de que no existía una obligación "contractual" de la is para con algún partido socialista miembro o afín, de hecho inexistentes en Nicaragua. Tal como había ocurrido con la insurrección en la Cuba de Batista, los aspectos épicos de la gesta popular urbana y rural ocuparon mentes y corazones en el escenario mundial antes de que se cayera en la cuenta de que las hazañas y mitos de la guerra civil eran el preludio necesario a la realidad concreta de una rebelión triunfante que se proyectaba como revolución en el poder. "La flexibilización táctica operada en el seno de la is, en el sentido de admitir, en ciertos casos, la lucha armada contra regímenes del tipo de Anastasio Somoza en Nicaragua, tuvieron como efecto crear condiciones de receptividad favorables para un discurso y una práctica políticos como los

37 Theo Rathgeber, op. cit., p. 288.

${ }^{38}$ Die Tageszeitung. Francfort/Berlin, 12 de septiembre de 1983, citado en El Parcial, Hamburgo, op. cit., p. IV.

${ }_{39}$ La más importante de esas expresiones la constituyó la ya mencionada constitución, en el Congreso de la is en Madrid en 1980 y por propuesta de Willy Brandt, de una comisión de ayuda a la revolución de Nicaragua, a cuyo frente el propio Brandt propuso a Felipe González, del PSOE, entonces en la oposición. Pero la comisión. de hecho, hizo poco o nada por Nicaragua.

to Prólogo de El Parcial, op. cit. 
de la socialdemocracia que, hasta entonces, había apenas languidecido en América Latina."4I

\section{El querer y el poder}

Pero al primer encandilamiento sucedió una percepción de recelo y continencia, derivados sobre todo de la independencia con que la revolución sandinista pretendía manejar su proyecto. Para no pocos políticos y partidos socialdemócratas europeos -iy qué decir del PLN de Costa Rica y de AD de Venezuela!- los victoriosos rebeldes parecian no sólo no tener intención alguna de acogerse al altruismo y experiencia de Europa, sino escoger una vía propia y más acorde con el espíritu y la obra de sus principales figuras históricas, Augusto César Sandino y Carlos Fonseca Amador, ambos enraizados en sustancias y esencias localistas y nacionales, entre ellas la de su antimperialismo acendrado y militante -antimperialismo yanqui para mayor precisión- que resultaba incomprensible para los patrones de razonabilidad comprehensiva de los políticos de allende el Atlántico.

La ignorancia, los prejuicios y ciertas simplificaciones no siempre ni necesariamente inocentes iban a marcar los primeros distanciamientos y los posteriores desencantos y animadversiones, después acentuados al impulso de incentivos de acción y guerra psicológicos desde los centros de poder de los Estados Unidos. La alternancia de impulsos de aceleración y regateos de freno, la elección de protagonistas y mediadores que signaban preferencias y orientaciones que provocaban rechazo o sospecha, fracturaron la primitiva buena disposición de los partidos socialdemócratas hacia la revolución nicaragüense, que por lo demás, debe recalcarse este detalle, nunca fue una adhesión y entrega plenas.

Los condicionamientos y prevenciones iban a reforzarse en partidos como el socialista portugués, el socialista y el socialdemócrata italiano y, de un modo menos frontal, en el PSOE de Felipe González; y en Iberoamérica, en forma agresora en el PLN costarricense y en $\mathrm{AD}$ venezolana. Con todo, la Is ofreció ejemplos de disparidad interna de criterios y enfoques, tolerancia que no evitó ciertas identificaciones occidentalistas transatlánticas que se sumaron a la visión eurocentrista del problema y complicaron el cuadro de situación. En este sentido debe anotarse la cíclica tendencia de algunos dirigentes y partidos de asumir las líneas básicas del discurso y la agresión de la administración Reagan hacia Nicaragua, sobre todo fundadas en la supuesta "desnaturalización" de los fines de la revolución sandinista - a la cual de todos modos Estados Unidos había sido adverso con James Carter-y en su presunta adscripción a modelos y tentaciones extracontinentales, o a su subordinación a proyectos extraños a la "comunidad americana" de naciones.

La revolución sandinista, anatematizada desde el norte, comenzó a ser hostigada y agredida desde cercanias geográficas, con respaldo económico y militar de Washington. Su crimen mayor no

${ }^{41}$ Atilio A. Boron, "La socialdemocracia europea y la transición democrática de América Latina", Documento de trabajo 10/1985, EURAL-Centro de Investigaciones Europeo-Latinoamericanas, Buenos Aires, Mimeo, 23 p. 
era tanto el de haber conmovido un modelo hegemónico, neocolonial y dependiente, sino el poder de su efecto y demostración en el istmo centroamericano. La rebelión armada salvadoreña, que en su fase activa tenía antecedentes previos al triunfo sandinista, fue caracterizada como un subproducto de exportación, demonologizada como de origen y sustento cubano e inclusive soviético.

El padrinazgo norteño ofrece una repetida tentación a las inclinaciones paternalizadas de cuño eurocentrista. Por costumbre o inercia, connotados dirigentes políticos latinoamericanos pavimentan las rutas de una subordinación cultural e ideológica no necesariamente pertinentes a los requerimientos y urgencias de pueblos y naciones del hemisferio. Y en buena parte de los casos, contradictorios con sus fines $\mathbf{u}$ opuestos a ellos.

Tras el comedimiento de la solidaridad y la simpatía, algunos lideres europeos de la Is adjuntaron recomendaciones, advertencias, reservas y prevenciones en que la modalidad paternalista encubria sesgos intervencionistas en algún caso asimilables a presión chantajista. Someter el apoyo o la ayuda a condiciones lesivas a la autonomia o a la independencia misma del gobierno que debe recibirlos, es la costumbre del neocolonialismo de posguerra en su relación con países que, a partir de su flamante independencia política, debieron negociar con sus antiguos colonizadores el trámite de su penoso y tardío crecimiento y desarrollo económicos. Nicaragua -del mismo modo con que lo procura el pueblo salvadoreño- no confrontó en su lucha liberadora el peso opresivo de una potencia expresado sin intermediarios, sino el poder de una oligarquía menor, de cuño familiar, asentada en una fuerza armada de uso privado.

Salvada la instancia de la dominación familiar somocista que además aportaba la impugnación de la incipiente burguesía incomodada por la desigual participación en el usufructo de las ganancias del régimen, los problemas mayores del gobierno revolucionario se vinculan con la reconstrucción de bienes y servicios afectados por la guerra civil, y con la edificación económica, social, cultural y, ¿por qué no?, moral, de un país asolado por más de 43 años de Somozas que a su vez continuaron una etapa de marginación iniciada en 1912, al caer ante los cañones y ametralladoras del ejército y la infantería de marina estadunidenses las defensas de El Coyotepe y la ciudad de Masaya.

En esa tarea ciclópea de levantar un país rico, aunque agostado por sus ordeñadores propios y foráneos, los actos de contención y freno, de hostigamiento económico y presión diplomática, además de los de agresión armada franca o solapada, no parecen ser el instrumento más idóneo para la meditación y la prudente elaboración a medidas de gobierno ecuménicas y a satisfacción de todos los sectores de la población. El gobierno de Managua tiene sobra-' das razones para sentirse agredido en varios frentes, en una nueva guerra que él no buscó ni deseó y que, naturalmente, obstruye y complica sus planes de reconstrucción. En esas circunstancias, exigirle -de un modo que no se requiere a los distintos agresoresel cumplimiento de requisitos y la observancia de pautas y conductas que serian congruentes para situaciones de paz y relativa normalidad como las que imperan en Europa, resulta tan injusto como peligroso para la subsistencia misma del proceso revolucio- 
nario. Insistir en esa tesitura, por otra parte, da pábulo a la sospecha y al resentimiento.

Con todo, los gobernantes de Nicaragua, increíblemente jóvenes e inevitablemente inmaduros en la ciencia de la administración de su patria, han demostrado una admirable capacidad de resistencia a la provocación multiplicada y de templanza y moderación frente a la agresión activa. Como la política consiente este tipo de comparaciones, podríamos afirmar que a tenor de la conducta que observan gran parte de los partidos socialdemócratas europeos hacia Nicaragua, los gobernantes y el pueblo de esta pequeña república, maguer su juventud e inexperiencia de gobierno, son mucho más merecedores del respeto mundial que los sabihondos y realistas políticos de la vieja Europa. Y que ciertos políticos latinoamericanos ávidos de poder, megalómanos y arrogantes en su petulancia de tierra caliente. Y que por ciertos equivocos de nomenclatura se suponen socialistas y actúan como si lo fueran en los foros europeos. En sus patrias latinoamericanas, en cambio, prefieren no mencionar esa palabra.

\section{Prioridades marginalizadoras}

Si nos hemos detenido con cierta morosidad en el caso de Nicaragua, es porque de entre todos los temas que sacudieron el interés y la conciencia de la is desde principios de la década de 1970 -excepción hecha de la tragedia chilena luego del derrocamiento de Salvador Allende- el de aquella pequeña república centroamericana sigue constituyendo, ya avanzada la segunda mitad de la década de 1980 , la piedra de toque de la posición global de la magna agrupación de la socialdemocracia europea no sólo frente a sus compromisos materiales y morales hacia sí misma, sino de cara a las naciones y pueblos del Tercer Mundo, especialmente en el ámbito de Iberoamérica.

Aquí Borón detecta avances de la Is propiciados "por los fracasos de la democracia cristiana, los populismos, las dictaduras militares y la guerrilla" asi como por el agobio "de la recesión mundial y el volumen fenomenal del endeudamiento externo". Tal coyuntura presenta rasgos más pronunciados en el extremo sur del continente, caracterizados "por una gran fluidez, por la obsolescencia de los viejos modelos y por la urgente necesidad de recomponer el Estado y el régimen político, todo lo cual precipita el accionar de fuerzas locales, afines a la socialdemocracia europea, que tratan de hacerse presentes en el escenario de la negociación nacional con fuertes avales internacionales". 42

La mención, al paso, de la democracia cristiana, añade la reflexión lateral de que es también esa fuerza organizada con características y objetivos mundialistas la que está presente en América y contiende pública o recoletamente con la IS. Sin compartir el optimismo de Borón en cuanto al fracaso de esta fuerza que es igualmente poderosa en Europa (por el contrario, sigue siendo decisiva en Chile y se ha impuesto electoralmente en Guatemala, El Salvador y con nombres alterados y alianzas diversas en Ecuador y República Dominicana, aunque el COPEO haya fracasado en Vene-

42. Atilio A. Borón, op. cit., p. 10-11. 
zuela), parecería obvio resaltar que en el curso de los años recientes la is se fue retirando discretamente de la región centroamericana, como si hubiese optado por ceder espacio y presencia a la democracia cristiana. Observadores y analistas más severos juzgan que este apartamiento tendría que ver con una división internacional de esferas de influencia, a partir del reconocimiento de que el istmo es parte del hinterland geopolítico-estratégico de Estados Unidos, potencia que ha escogido como aliados más confiables a los democristianos.

$\mathrm{Si}$ este reparto de presencias e influencias es correcto, la is habría optado decididamente por el menos ríspido ámbito sudamericano, de acuerdo con la siguiente interpretación:

América Latina constituye el área del Tercer Mundo y en especial la parte meridional del continente, que guarda más semejanzas con lo que ha sido el escenario clásico de la socialdemocracia: es a la vez Occidente y Tercer Mundo; sus instituciones sociales fundamentales, sus sistemas culturales, su tradición politicoideológica y sus aparatos organizativos surgen de la misma fuente civilizacional, cosa que no ocurre en Asia o Africa, por ejemplo. En un sentido profundo toda América, de norte a sur, es una colección de fragmentos diversos producidos por la expansión de la cultura europea y ello hace que sea factible hallar en esas tierras interlocutores homogéneos, afinidades de proyectos, discursos y bases sociales. ${ }^{43}$

A esa configuración, Borón añade que la región constituye también "un espacio económico crecientemente disputado por las grandes potencias económicas y en esta discusión Europa no puede estar ausente". Por lo demás y sin caer en un reduccionismo economicista, el continente configura una verdadera "clase media' entre las naciones del Tercer Mundo, con un nivel de ingresos -insiste Borón- muy superior al del resto, con amplios mercados susceptibles de significativos crecimientos, rico en recursos naturales de todo tipo y con una capacidad potencial de negociación internacional que lo coloca en una posición destacada en el Tercer Mundo". Finalmente, la expansión económica de los capitales europeos desde la década de 1970 colocó ta impronta de una equivalente "europeización" de la política y de algunos ingredientes culturales y sociales afines.

El tradicional rechazo a las formas de penetración de los Estados Unidos, aunque mucho más amenguado por obra de una consecuente "culturalización" que impregna desde hace varios lustros todos los medios de prensa y dispositivos de propaganda y acción psicológica neocolonizadores, sigue impermeabilizando a vastas capas de poblaciones y reteniéndolas como potenciales resistentes a la influencia imperial. Problemas como el de la deuda externa y otros que fracturan la otrora confiabilidad de las clases medias y sectores naturalmente aliados al sistema neocolonial, abren una perspectiva de confrontación de insospechables derivaciones. Actitudes como las adoptadas por los gobiernos de Alán Garcia en Perú y Josẻ Sarney en Brasil en el orden financiero, señalan no obstante sus aspectos ambiguos o incoherentes que los fermentos de inconformidad y desajuste pueden dar paso a un generalizado

${ }^{43}$ Ibid., p. 11. 
descontrol de la región. En este renglón resulta irónico que los banqueros y prestamistas de Europa estén no menos alarmados que los de Estados Unidos, Canadá y Japón.

Ante este estado de cosas, resulta todo un símbolo lo ocurrido en junio de 1986, durante la realización del primero de los congresos de la is en América Latina. En Lima y en un clima de tensión total y bajo amenazas frustradas de agresión a los congresistas del movimiento "Sendero Luminoso", las delegaciones procedentes de todo el mundo debieron clausurar sus deliberaciones 24 horas antes de lo previsto, al tiempo que en varias cárceles peruanas fuerzas policiales y militares procedian a una meticulosa masacre de prisioneros políticos, que el propio mandatario peruano condenó como inhumana y genocida, disponiendo además la exoneración de los principales responsables, su arresto y procesamiento ulteriores.

Una de las asistentes a la reunión, la señora Wieczorek-Zeul, aunque en relación con otro aspecto del cónclave, observó para la prensa germana: "En América Latina existe, pues, otra concepción de valores politicos y culturales que en Europa". ${ }^{44}$ Este maravilloso descubrimiento ilustra como pocos el grado de lejanía y ajenidad prevalecientes en los círculos políticos que teóricamente están más cerca de nuestra América y sus conflictos. No es, empero, el único distanciamiento. El documento final del cónclave podría estimarse como entre los más débiles de los producidos por las asambleas de la is en los últimos años, en relación con América Latina y el Tercer Mundo y, por cierto, conceptuarse las declaraciones emitidas respecto a Nicaragua y El Salvador como concesiones tributarias a los sectores más conservadores de la organización, además de un retroceso en relación a posiciones anteriores, mucho más firmes y claras.

Si la tendencia a la concesión y la debilidad es el nuevo signo de la IS. perderá en Iberoamérica lo que obtuvo tan trabajosamente en el curso de los últimos lustros.

${ }^{44}$ Die Tageszeitung. Francfort/Berlín, 24 de junio de 1986. 